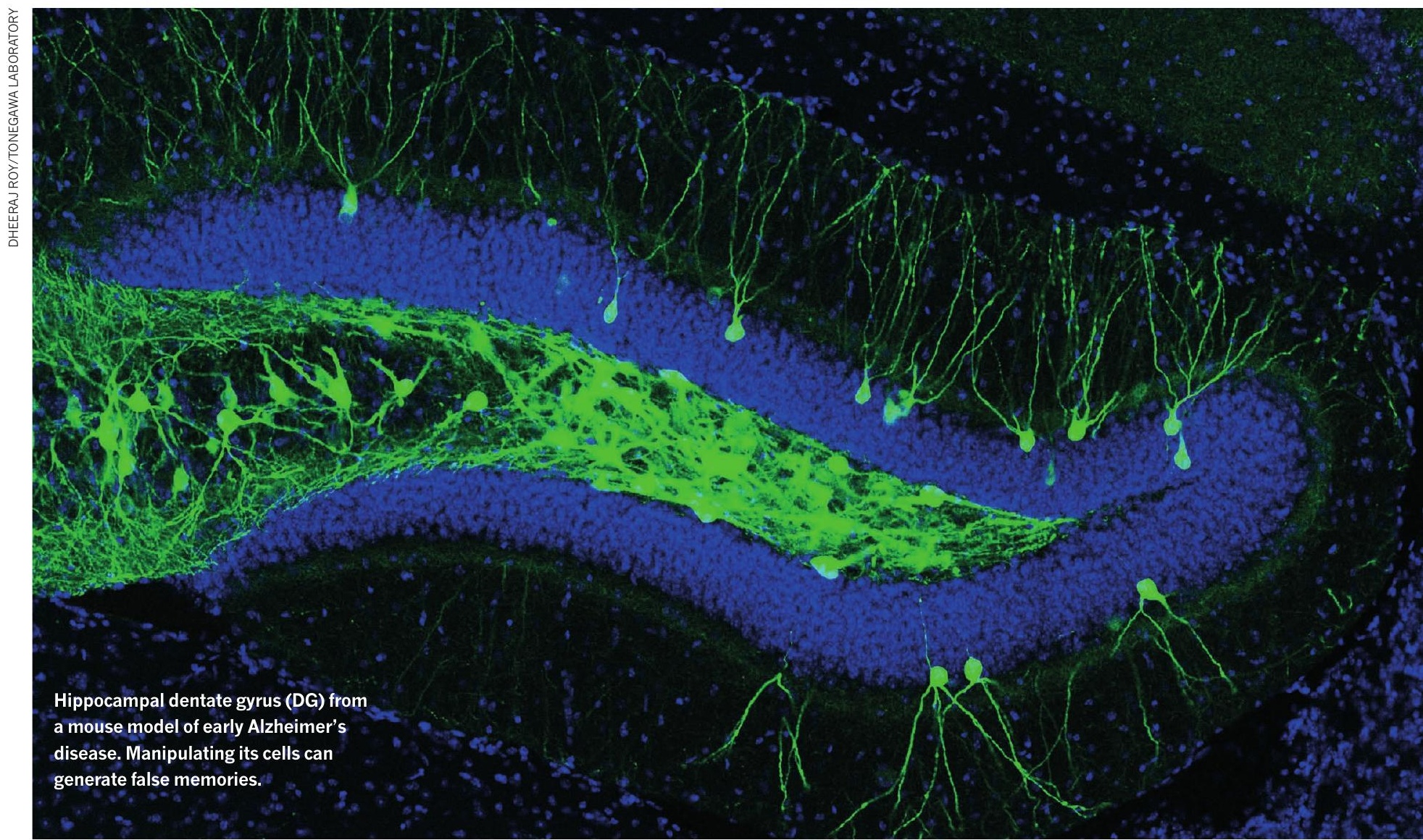

\title{
ACCESS GRANTED
}

\section{International collaborations are rising, but not enough to put Japan on the international researcher circuit.}

\section{BY DANIEL HURST}

$\mathrm{T}$ he Japanese government recognizes the relative isolation of Japanese science as a problem.

"Strategic international development combined with science and technology diplomacy is indispensable for Japan," asserts the 2016 White Paper on Science and Technology, a blueprint for Japan's goal of becoming a 'super-smart' society.

But the call is not new, as disaster management researcher Rajib Shaw points out. He has witnessed the country's efforts to deepen its global connections over nearly 25 years, since coming to Japan as a student. In most cases, new schemes to promote collaboration are simply repackaged versions of old schemes, he says: "It's like old wine in a new bottle."

Shaw has spent 14 years working in academic institutions in Japan and is now professor at Keio University, and chair of the UN Office for Disaster Risk Reduction's Science Technology Advisory Group. He leads a component of a joint Japanese-Bangladeshi project, looking at flood risk in Bangladesh.

Mindsets need to change, says Shaw. Not enough Japanese researchers are eager to publish their papers in English and present to international conferences, he says. This reduces their impact.

\section{PAIRING UP}

Nature Index data show the government has made some progress against these goals, although the results are mixed. Only about half of the papers published by Japanese researchers have an international co-author, compared with about three-quarters of papers in the United Kingdom and Germany.

However, the number of international partnerships involving Japanese researchers has risen from 20,106 in 2012 to 33,439 in 2017 an increase of more than $65 \%$. The United States remains Japan's most frequent collaborator in producing high-quality articles across four broad science categories, although the pair's total collaboration score declined $4.7 \%$ over the same period.

In 2013, for instance, researchers from the RIKEN-Massachusetts Institute of Technology (MIT) Center for Neural Circuit Genetics reported in the journal Science on how they could manipulate cells in the mouse hippocampus to generate false memories. More recently, they have published papers on memory in Nature that offer potential clues about depression and Alzheimer's disease.

The centre, headed by Nobel laureate, Susumu Tonegawa, brings together researchers from the RIKEN Brain Science Institute in Saitama and the Picower Institute for Learning and Memory at MIT. Over the past six years, RIKEN has engaged in 1,868 partnerships with international institutions, making it Japan's second most collaborative institution after The University of Tokyo.

Nature Index data show Japan's collaboration score with China surged by $41 \%$, ranking it as Japan's third favourite collaborator after 
Germany. Chinese and Japanese researchers have collaborated on projects looking, for example, at cancer and hepatitis $\mathrm{B}$ and $\mathrm{C}$ risk factors and control measures. The top-ranked areas of collaboration between the two countries in the index were in the physical sciences and chemistry fields.

\section{BRAIN GAIN}

One way of raising Japan's profile, according to the Science and Technology Basic Plan, is to "bolster global brain circulation" - which means encouraging Japanese researchers to conduct research abroad and international researchers to do the same in Japan. As part of these efforts, the government-funded Japan Society for the Promotion of Science helps organize exchanges for young researchers.

The government's World Premier International Research Center Initiative (WPI) also aims to build "globally visible" research centres that attract leading researchers from abroad. Mathematician, Motoko Kotani is a director of one of these centres, the Advanced Institute for Materials Research (AIMR) at Tohoku University.

She says $40 \%$ of its members are non-Japanese. By comparison, the average share of foreign faculty members in Japanese national universities is $4 \%$, according to figures compiled by the Japan Association of National Universities.

While individual Japanese researchers have contributed to global academic communities, institutions have a limited international presence, says Kotani.

Much effort has gone into supporting premier universities to work internationally, says Akiyoshi Yonezawa, the director of the Office of Institutional Research at Tohoku University. But he worries a side-effect will be a greater divide between the top- and second-tier universities.

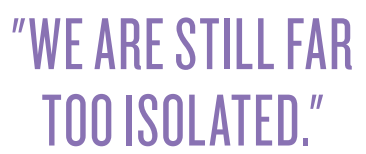

"The top universities may be in a process of changing, but at the second-tier universities performance is going down quite rapidly," he says. He points to analysis by Professor Nagayasu Toyoda showing a growing disparity in the number of clinical medicine papers published by the higher and lower-ranked university departments.

"This is very dangerous because research performance cannot be sustained only by the top universities. We need to have a larger pool of talents." Yonezawa's concerns are not yet reflected in the Nature Index, as output from the group of 11 top research universities has declined at a similar pace to all other academic institutions between 2012 and 2017.

\section{INTERCEPTING TRAFFIC}

The most obvious obstacle to increasing Japan's international collaboration is the language barrier. Most of the older generation have "a very serious problem with English, especially in humanities and social sciences," says Yonezawa.

While younger generations are gradually gaining better English skills, "compared with other east Asian countries or south-east Asian countries, we are still too far isolated," he says.

Shaw of Keio says the language barrier was a "major issue" when he first came to Japan. He found that students and some senior researchers hardly read any English literature. The situation is gradually changing, although he says he has seen several researchers giving international presentations about global collaborative projects with slides in Japanese.

Kotani says the AIMR has sought to accommodate international members by adopting English as the official language, but adds: "most Japanese research grants can only be applied for in Japanese, and there are few bilateral or international joint research grants."

\section{JAPAN'S TOP COLLABORATORS}

Over the past six years, Japan has cultivated strong scientific links with the United States, though the number of papers the two countries have co-authored has declined slightly. The collaboration score (CS) is derived by summing the contribution of authors to articles in the index in both countries.

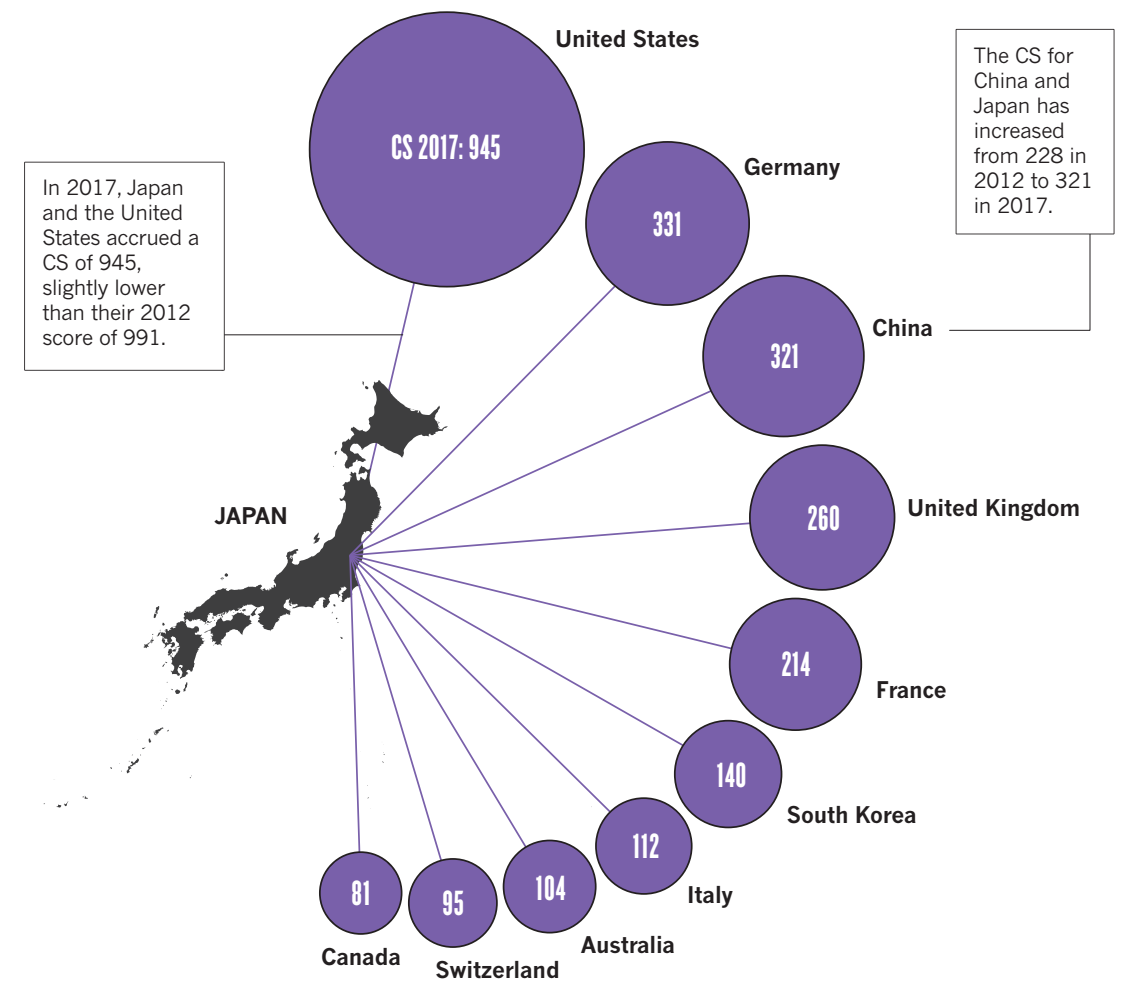

\section{INTERNATIONAL COOPERATION}

Slightly more than half of papers authored by researchers in Japan in 2017 had a co-author outside the country. This proportion is lower than the leading countries in the Nature Index except China and the United States.

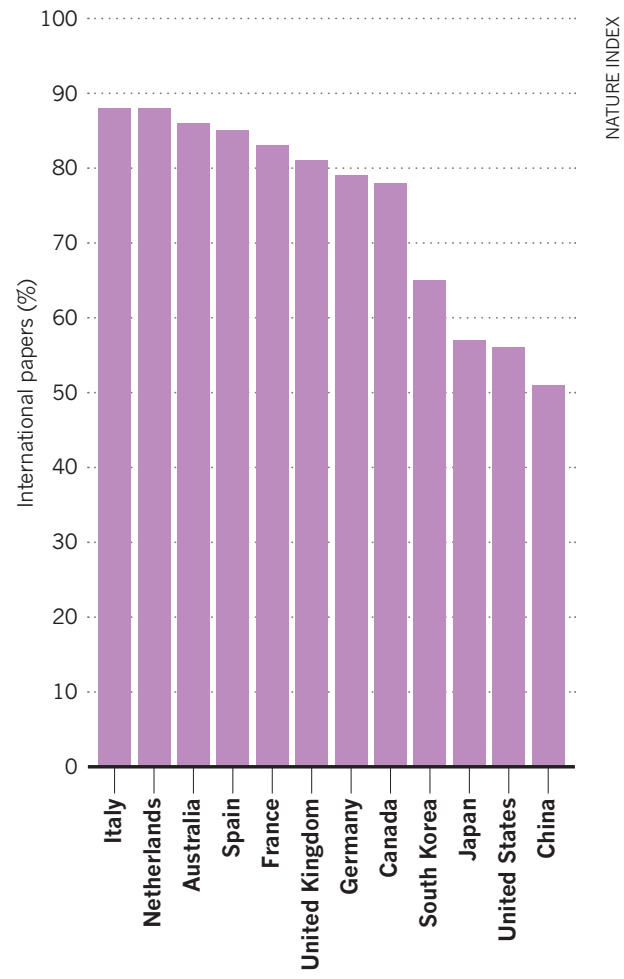

